\title{
Preventing Highway Crashes by Raising The Legal Minimum Age for Drinking: An Empirical Confirmation
}

\author{
Alexander C. Wagenaar
}

\begin{abstract}
In recent years there has been increased interest in reducing the massive social costs due to alcohol-related motor vehicle crashes. Raising the legal minimum age for purchase and consumption of alcoholic beverages has been proposed as one way to reduce alcohol-related crashes among young drivers. Currently, many states are raising the legal age, in contrast to the trend towards lower legal drinking ages in the early 1970s. Recent studies of the effects of raising the drinking age are reviewed, and results from a controlled multiple timeseries evaluation of the experience in Michigan are presented. Significant 11 to $28 \%$ reductions in alcohol-related crash involvements are shown to be attributable to the raised drinking age in Michigan. Suggestions for further research and discussion of policy implications are included.
\end{abstract}

In recent years there has been increased interest in reducing the massive social costs due to alcohol-related motor vehicle crashes. Citizen activist groups such as Mothers Against Drunk Drivers have emerged, and increasing numbers of states are modifying laws and public policies in an effort to reduce alcohol-impaired driving and its consequences. Nevertheless, research has not unequivocally demonstrated the effectiveness of many of these law and policy changes in reducing alcohol-related motor vehicle crashes (Jones \& Joscelyn, 1978).

One public policy that has been modified

Dr. Wagenaar is an Assistant Research Scientist at The University of Michigan Highway Safety Research Institute, Ann Arbor.

This study was supported in part by grant 1H84AA4791-01 from the United States National Institute on Alcohol Abuse and Alcoholism. in at least 19 states in the past few years and has had a significant effect on alcohol-related crash involvement is the legal minimum age for purchase and consumption of alcoholic beverages. Young adults have the highest rates of alcohol-related crashes of any age group (Cameron, 1977; Joscelyn, Jones, \& Ruschmann, 1981) and are therefore an important target group for the reduction of highway casualties associated with alcohol use. Concern over the magnitude of the alcohol-related crash problem among youth, along with growing research evidence of the efficacy of higher legal drinking ages in reducing this problem, have contributed to a recent trend toward raising minimum drinking ages. This trend is in contrast to the early 1970 s when 29 states reduced their legal drinking ages. Several studies of the effects of modifying the legal drinking age are reviewed below, 
followed by a more detailed discussion of a continuing controlled evaluation of the experience in Michigan.

More than a dozen studies of the effects of lowering the drinking age in various states and Canadian provinces have been reported. Comprehensive reviews of these investigations have been provided by Smart and Goodstadt (1977), Whitehead (1977, 1980), and Wagenaar (1980) and will not be repeated here. It is simply noted that these reviews, after giving more weight to investigations with the best research design and analysis methods, revealed that lowering the drinking age resulted in about a $25 \%$ increase in alcohol-related motor vehicle crash involvement among young drivers.

Several investigations of jurisdictions that have raised the drinking age have already been reported. Hingson, Scotch, Meyers, and others (1981) are evaluating the effects of Massachusetts' increase in drinking age from 18 to 20 (effective April 1979). Initial analyses of traffic fatality data for Massachusetts (using upstate New York for comparison) revealed no clear effect of the higher drinking age on youth fatal crash involvement. Surveys before and after the law went into effect led the authors to conclude that the quantity of alcohol drunk and drinkingdriving behavior among young people (based on self-reports via telephone interviews) did not change significantly as a result of the new law. It is worth noting, however, that the proportion of 16-19 year old Massachusetts youths who reported driving after drinking decreased from $51 \%$ before the raised drinking age to $42 \%$ after. Separate results for 18-19 year olds, the focus of the new law, were not discussed in this preliminary report.

Voas and Moulden (1980) briefly reported analyses of the effect of Maine's raising the drinking age from 18 to 20 (effective October 1977). Their initial analyses of 18 year old drivers indicated larger reductions in single-vehicle nighttime male crashes (many of which involve alcohol) than in singlevehicle daytime crashes (few of which involve alcohol). They estimate an average crash reduction of 2.4 per month among 18 year old drivers over the first year with the new law. No effect was found for 19 year olds. The authors point out that these results were based on early analyses of a short postchange period in only one small state and that additional results from other states are needed before any conclusions on effects of higher drinking ages are made.

Wagenaar (in press, a) also examined Maine's experience with a higher drinking age. Forty-eight months of baseline and 26 months of post-intervention crash data were analyzed in a time-series design, comparing young drivers with older drivers, alcoholrelated crashes with non-alcohol-related, and examining Pennsylvania as a comparison state with no drinking age change. Alcohol-related property damage crash involvement among 18 and 19 year old Maine drivers was 17 to $22 \%$ lower than expected had the drinking age not been raised. Results for injury-producing crashes were not as clear-cut, and no unequivocal effect on these more serious crashes was found.

Klein (1981) also evaluated the effect of Maine's increase in drinking age. Nighttime crash involvement among males and singlevehicle nighttime male crash involvement were used as proxies for alcohol-related crashes. Time series analysis using data from 1974 through 1979 revealed significant crash reductions from 14 to $20 \%$ after Maine's higher legal age was implemented.

Maxwell (1981) conducted a similar timeseries analysis on Illinois data from 1977 through 1980 . A significant $9 \%$ decrease in single-vehicle nighttime male crash involvement among 19 and 20 year old drivers was found after Illinois raised its drinking age from 19 to 21 (effective January 1980). In contrast, no significant changes in these measures were found for drivers under 19 or over 20.

Filkins and Flora (1981), using a partitioned chi-square statistical analysis technique, examined random samples of crashinvolved youth in Michigan. Significant 11 to $24 \%$ reductions in alcohol-related crash involvement among 18-20-year old drivers were found after the drinking age was raised. Separate analyses of fatal crashes, however, identified no significant changes associated with the higher drinking age. The authors concluded that the overall results clearly demonstrate that the legal drinking age in- 
fluences drinking-driving patterns among young drivers.

Wagenaar (1981) analyzed a $20 \%$ random sample of all reported motor vehicle accidents in Michigan between January 1972 and December 1979. Using a multiple time-series design, he compared the frequency of alcohol-related crashes among young drivers to the frequency of non-alcohol-related crashes and the overall crash involvement of young drivers with that of older drivers. Results showed an cstimated $18 \%$ reduction in alcohol-related crashes among young drivers that was associated with Michigan's increase in drinking age from 18 to 21 (effective December 1978). Separate analyses were also conducted of fatal crash involvement. The results did not reveal any significant effect of the raised drinking age on this small subset of crashes.

Williams, Zador, Harris, and Karpf (1981) analyzed fatal crash involvement from 1975 to 1980 in nine states that raised the drinking age, comparing them to neighboring states with unchanged drinking ages during the period studied. Because two of the states raised the drinking age from 18 to 19 and included grandfather clauses permitting those already 18 to continue to drink, crash data for the first 12 months after the legal changes were excluded. Eight of the nine states experienced decreases in youths' nighttime fatal crash involvement after the drinking age was raised; crash reductions ranged from 6 to $75 \%$. The smallest estimated reduction applied to Massachusetts, for which a nonsignificant $6 \%$ reduction in nighttime fatal crash involvement was found. Averaging across the nine states, the authors concluded that raising the drinking age in any given state should result in a $28 \%$ reduction in nighttime fatal crash involvement among the age group affected by the change.

Vingilis and Smart (1981) assessed the initial effects of Ontario's increase in drinking age from 18 to 19 . The law included a grandfather clause, permitting those who were 18 before implementation of the higher legal age to continue to consume alcoholic beverages. Aggregate analyses of drinkingdriving convictions and fatal crash involve- ment among $16-21$ year olds for a multi year period revealed no significant changes associated with the drinking age increase. These results should be interpreted cautiously for several reasons. First, only a small effect of the new law was expected, since the legal age was increased by only one year with a grandfather clause excluding 18 year olds who already had the right to drink. With the grandfather clause and analyses of only the first year under the new law, it is clear that the drinking privileges of only a small proportion of young Ontario drivers were revoked during the study period. Further, convictions and fatalities are insensitive measures, responding only to major shifts in drinking-driving behavior by a sizable proportion of the population. Because of these considerations, it is important to consider these results "preliminary," as Vingilis and Smart point out.

Finally, the National Highway Traffic Safety Administration (1982) used hospital emergency room data to compare serious injury rates in states with low drinking ages (18 or 19) and states with high drinking ages (20 or 21 ). States with higher drinking ages had lower nighttime serious injury rates among youths under 21 than states with lower drinking ages.

Most of the studies reported to date have found significant effects of the legal minimum drinking age on youths' alcohol-related crash involvement. Significant effects of raising the legal age appear less likely to be observed when (1) the drinking age is changed only one year (e.g., from 18 to 19), (2) a grandfather clause is included in the new law, and (3) limited short-term postchange data are available. Analyses based on small numbers of drivers (for example, only those involved in fatal crashes) also are less likely to identify a significant effect.

The evaluation reported below examined all reported crash-involved drivers in Michigan from January 1972 through December 1979. The multiple comparison groups included in the evaluation design and the data analysis methods used are reviewed in some detail, followed by a presentation of the findings and discussion of implications for further research and drinking-driving countermcasure development. 


\section{METHOD}

Design. The nonequivalent multiple timeseries design was used to evaluate the effects of Michigan's increase in legal drinking age. The time-series design has a high level of internal validity and therefore provides results that can be interpreted in causal terms with confidence (Cook \& Campbell, 1979). As a result, it is the design of choice for evaluating crash countermeasure policies and programs, where random assignment is not possible, and extensive longitudinal data are available.

The multiple time-series design involves a comparison of a series of observations over time expected to be affected by a policy change with control series not expected to be affected. In this research, the postulated causal relationship was between changing the legal drinking age and traffic crashes. The design, as used in the present investigation, is shown in its simplest form in Figure 1 , where each $O_{i}$ represents the number of drivers involved in crashes in a particular month, I represents the intervention (raising the drinking age), $n_{1}$ is the number of monthly observations before the drinking age was raised, and $n_{2}$ is the number of monthly observations after the drinking age was raised. The second row in the design diagram represents a comparison time series, not influenced by the intervention.

Although this simple diagram depicts only one experimental and one comparison series, multiple measures of motor vehicle crash involvement and multiple comparison groups were included in the design. The broadest of the three levels of comparisons was an analysis of two different states, one that had raised the drinking age in the late 1970s (Michigan from 18 to 21 ) and one with no such legal change (New York, with a drinking age at 18 throughout the study period).

In Michigan, comparisons were made be-

FIGURE 1

NONEQUIVALENT MULTIPLE TIME-SERIES DESIGN

$$
\begin{aligned}
& \mathrm{O}_{1} \mathrm{O}_{2} \mathrm{O}_{3} \ldots \mathrm{O}_{\mathrm{n}_{1}} I \mathrm{O}_{\mathrm{n}_{1}+1} \mathrm{O}_{\mathrm{n}_{1}+2} \mathrm{O}_{\mathrm{n}_{1}+3} \ldots \mathrm{O}_{\mathrm{n}_{1}+\mathrm{n}_{2}} \\
& O_{1} O_{2} O_{3} \ldots O_{n_{1}} \quad O_{n_{1}+1} O_{n_{1}+2} O_{n_{1}+3} \ldots o_{n_{1}+n_{2}}
\end{aligned}
$$

tween young drivers directly affected by the drinking age change and their proximal peers not affected by the change. Therefore, the crash involvement experience of 18-20 year olds was compared to that of 21-23 year olds, the 3-year age cohort most similar to the focal 18-20 group, but yet legally enfranchised drinkers throughout the study period. Drivers ages 16-17 were also examined to assess any possible "trickle-down" effect of raising the drinking age. Finally, the crash involvement experience of older drivers (24-45) was analyzed to provide further comparisons with the crash experience of young drivers. The same four age groups were also analyzed for New York, the control state in the design.

Within each state/age-group combination, alcohol-related crash involvement was compared with non-alcohol-related crash involvement. Since a raised drinking age is expected to affect the frequency of alcoholrelated crashes and have no effect on nonalcohol-related crashes, comparing these two catagories indicated whether observed changes in crash frequencies were due to drinking age changes or other coincident factors.

Finally, two indicators of alcohol-related and non-alcohol-related crashes were analyzed. The first was based on information provided by police officers investigating traffic crashes. Crash report forms in many states include an indication of the officer's judgement concerning whether or not the driver had been drinking at the time of the crash. In Michigan, a separate dichotomous forced-choice item on the statewide standardized crash report requires the investigating officer to identify the driver as nondrinking or drinking. This item is independent of (1) any judgement that alcohol "caused" the crash, (2) whether or not the driver was arrested for Driving Under the Influence of Liquor (DUIL), and (3) results of any blood alcohol concentration test that might have been administered. The data resulting from this item are a reasonably good indicator of the involvement of drinking drivers in crashes.

In contrast, New York's indicator of alcohol-involved crashes is based on police officers' identification of "apparent" factors 
contributing to the crash. These are selected from a list of 25 to 50 possible choices, including alcohol consumption. The resulting data are a less adequate indicator of alcohol-related crash involvement because, although alcohol use interacts with many other crash causes, an officer must select one factor as the primary cause of the crash. For example, an officer might select "driver fell asleep" or "unsafe speed" rather than "alcohol involvement," when in fact heavy drinking may have been the cause of falling asleep or speeding.

Many individuals dismiss any results based on police-reported drinking, because such data are generally considered unreliable. It must be recognized, however, that wide differences exist among states in the quality of police-reported information on drinking by crash-involved drivers. These data should be used as one indicator of alcohol involvement in those states where standardized recording systems are adequately developed.

To provide a consistent measure of alcohol-related crashes across states and to control for reliability and validity in policereported alcohol involvement, an indirect indicator of alcohol-related crashes was analyzed separately. This indicator was male drivers involved in single-vehicle nighttime crashes. Previous research (Douglass, Filkins, \& Clark, 1974) has shown that a high proportion of single-vehicle nighttime male crashes involve drinking drivers. Daytime crashes were used as an indirect indicator of non-alcohol-related crashes.

In summary, the full three-level design involved the following comparisons:

1. A state that raised the drinking age was compared with a state with an unchanged drinking age.

2. Crash involvement experience of young drivers was compared to that of older drivers.

3. The frequency of alcohol-related crash involvement was compared to the frequency of non-alcohol-related crash involvement.

In addition, two indicators of alcohol-related crashes (police-reported drinking and single-vehicle nighttime male crashes) were analyzed; and all of the crash involvement indicators were analyzed in two separate groups depending on the severity of the crash. The first group consisted of crashes that caused property damage only, the second crashes that resulted in at least one personal injury or fatality.

Separate analyses of fatal crash involvement were not conducted, because the frequency of alcohol-related fatal crash involvement among young drivers in a single state is too low for statistical analysis purposes. Even in a populous state such as Michigan, the number of 18-20 year old drivers involved in alcohol-related fatal crashes is only about 0 to 20 per month. The random month-to-month (and year-to-year) fluctuation dominates the series variance, making detection of any significant intervention effect very difficult. In spite of the substantially increased effort required to process millions of nonfatal crash records (versus thousands of fatalities), the entire spectrum of crashes at varying levels of severity provides more adequate indicators for impact evaluation. The need to analyze the larger numbers of nonfatal crashes is particularly great if public policy or programmatic changes are implemented in a single jurisdiction and/or focused on a limited target population.

Analysis. Ordinary least squares regression and other common statistical procedures could not be used for the present analyses because they assume independent observations, that is, no serial correlation. A series of observations on the same unit over time, such as the crash series analyzed here, are usually autocorrelated, violating the assumption of independence required for the use of standard statistical procedures. As a result, an alternate method, Box-Jenkins time series analysis (Box \& Jenkins, 1976), was used.

The Box-Jenkins approach involves modeling autocorrelation in time-series variables to produce unbiased estimates of error variance in the presence of serially correlated observations. Recent methodological developments in the use of intervention models (i.e., transfer functions), along with the Auto-Regressive Integrated Moving Av- 
erage (ARIMA) modeling strategy, make these techniques the best currently available for the analysis of time-series quasi-experiments (Box \& Tiao, 1975; Hibbs, 1977; McCleary \& Hay, 1980). The techniques identify a wide variety of patterns in the dependent time-series variables, provide a sensitive test of intervention effects, and permit the analysis of a variety of intervention effect patterns. [See Gottman (1981, p. 50 ) for a description of possible intervention effect patterns.]

The purpose of the data analyses in this investigation was to determine the impact of changes in legal drinking age on each dependent variable. After the effects of the legal change on each variable were determined through the statistical procedures described below, the effects were compared across those measures expected to be influenced by the legal change and those not expected to be influenced by the intervention, as called for by the research design.

Since traffic crash time-series often contain large seasonal components, the general multiplicative seasonal model was considered for each dependent series. The general seasonal ARIMA model is shown in Figure 2.

It is important to realize that the ARIMA model is not based on a theory concerning the causes of the dependent series. It is a model to describe the long-term regularities in the series due to any number of (most likely unidentified) causes. The ARIMA model for each variable, therefore, must be empirically determined by examining a scries of observations of that variable.

Theoretical autocorrelation and partial autocorrelation functions corresponding to various ARIMA models have been described by Box and Jenkins (1976). In the present study, a preliminary ARIMA model was identified for each series by examining the estimated autocorrelations and partial autocorrelations and assessing the degree to which the actual autocorrelations fit the theoretically expected patterns. The simplest model that could plausibly account for the behavior of the series was selected.

A first-order moving average, first-order seasonal moving average model on the seasonally differenced series, was identified for the majority of the dependent variables. In terms of the general model in Figure 2, the specific baseline model for most of the series was

$$
\mathrm{z}_{\mathrm{t}}=\frac{\left(1-\mathrm{\theta}_{1} \mathrm{~B}^{12}\right)\left(1-\theta_{1} \mathrm{~B}\right) \mathrm{u}_{\mathrm{t}}+\alpha}{1-\mathrm{B}^{12}} .
$$

After an ARIMA model of the series was identified, intervention models representing hypothesized effects of the raised drinking age were added to the baseline model.

FIGURE 2

GENERAL SEASONAL ARIMA MODEL

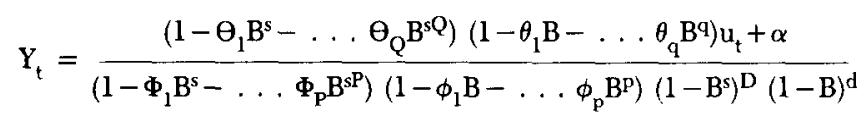

$$
\begin{aligned}
& \mathrm{p}=\text { the order of the auto-regressive process } \\
& \text { d } \quad=\text { the degree of non-seasonal differencing } \\
& \mathrm{q} \quad=\text { the order of the moving-average process } \\
& \text { p = the order of the seasonal auto-regressive process } \\
& \text { D = the degree of seasonal differencing } \\
& Q=\text { the order of the seasonal moving average process } \\
& \mathrm{s} \quad=\text { the seasonal span } \\
& \Phi_{1} \text { to } \Phi_{\mathrm{P}}=\text { the seasonal auto-regressive parameters } \\
& \phi_{1} \text { to } \phi_{\mathrm{p}}=\text { the regular auto-regressive parameters } \\
& \theta_{1} \text { to } \theta_{\mathrm{Q}}=\text { the seasonal moving-average parameters } \\
& \theta_{1} \text { to } \theta_{\mathrm{q}}^{\mathrm{Q}}=\text { the regular moving-average parameters } \\
& \mathrm{u}_{\mathrm{t}} \quad \mathrm{q}=\text { the random (white noise) error component } \\
& \alpha \quad=\text { a constant } \\
& \text { B = the backshift operator such that } \mathrm{B}\left(\mathrm{z}_{\mathrm{t}}\right) \text { equals } \mathrm{z}_{\mathrm{t}-1}
\end{aligned}
$$


In addition, since several reports found that the fuel shortage, the national maximum 55 $\mathrm{mph}$ speed limit, and related factors in early 1974 resulted in a reduction in motor vehicle crashes (Chu \& Nunn, 1976; O’Day, Minahan, \& Golomb, 1975; Wiorkowski \& Heckhard, 1977), parameters representing the effects of this major exogenous influence were included in the analyses of variables exhibiting a substantial decrease in frequency in early 1974 .

All of the exogenous factors, including the drinking age, were modeled with the simple shift form of the general transfer function model developed by Box and Jenkins:

$$
\omega \mathbf{I}_{t-b}
$$

where $\omega$ is the parameter estimating the shift or change in level of the series, $I_{t}$ is a step function equal to zero prior to the intervention and one after intervention implementation, $t$ identifies the month of the time series (e.g., January $1972=1$, December $1979=96)$, and $b$ is the amount of delay or dead time after implementation of the intervention before any impact is expected. No delay parameter was included in the analyses because, given previous research on drinking age effects, the initial effects of the change in legal age were expected in the month immediately following the law enactment. In contrast to the ARIMA baseline models, which were empirically constructed to account for observed regularities in each series, inclusion of intervention parameters was based on hypothesized effects and known causes of changes in the frequency of crash involvement.

After the nature of the ARIMA component was identified based on a plot of the raw data and autocorrelation and partial autocorrelation functions, and the appropriate intervention model components were added, preliminary estiniates of the parameters of the identified model were calculated. These preliminary estimates were input as starting values for the computer estimation program BMDQ2T (Liu, 1979). Since the models are intrinsically nonlinear, BMDQ2T uses the Gauss-Marquardt method to obtain estimates of the parameters. The unconditional least squares (i.e., back- casting) cstimation algorithm was used rather than conditional least squares because seasonal moving average models were being estimated; Box and Jenkins (1976) recommend unconditional least squares estimation for such models.

Estimation results were then evaluated in terms of the multiple criteria advocated by Box and Jenkins (1976). If any inadequacies were found, the model was respecified, reestimated, and reevaluated until a parsimonious model was obtained that adequately accounted for all of the autocorrelation patterns in the original crash time series.

The values of the intervention model parameter estimates, along with unbiased estimates of their standard errors, were used to determine the changes in crash involvement associated with raising the drinking age. In addition, where such changes were evident, these values were used to assess the direction and magnitude of the impact.

In summary, the data analysis strategy was as follows. First, a baseline time-series model was specified on the basis of a plot of the raw series and the estimated auto- and partial autocorrelation functions. Second, intervention parameters for the major exogenous factors were added to the baseline model, and the combined baseline and intervention model was estimated. The combined model was evaluated; and the specification, estimation, and evaluation process was repeated, if necessary, until an adequate model was obtained. The statistical significance and magnitude of the intervention model parameter estimates were used to identify the impact of a legal change in drinking age on that particular time series dependent variable. This comprehensive modeling strategy, using multi-year baseline data, provided estimates of the net change in crash involvement associated with an increase in legal drinking age, controlling for the effects of long-term trends, seasonal cycles, and other factors influencing motor vehicle crash frequency. The analysis strategy was repeated for each dependent variable, with the results compared across: (1) indicators of alcohol-related crash involvement and indicators of non-alcohol-related crash involvement; (2) experimental age groups (drivers under 21) and 
comparison age groups (drivers over 21 ); and (3) two states, Michigan, which changed its drinking age, and New York, which did not.

\section{RESULTS}

Results revealed substantial reductions in alcohol-related crash involvement among young drivers after the drinking age was raised in Michigan. Net changes in property damage crash involvement associated with the increase in drinking age are summarized in Table 1. When the percent change ${ }^{1}$ figures are examined for variables exhibiting a significant shift in the first month after the drinking age change, the following findings emerge.

First, alcohol-related property damage crash involvement decreased significantly for drivers ages 18-20 - the target of the increase in drinking age. The pronounced decrease in alcohol-related property damage crash involvement was evident for both police-reported drinking drivers (Figure 3) and single-vehicle nighttime male drivers (Figure 4). ${ }^{2}$ The unusually large number of crash-involved drivers in December 1978 may reflect one last binge on the part of the young drivers, before alcohol was no longer legally available beginning December 23. The apparent upward trend during 1979 does not indicate that the effect of the law change is temporary, but rather simply re-

'Percent change figures are based on the first 12 months after the increase in drinking age and were calculated as follows:

$$
\% \text { change }=\frac{12 \omega}{\left(\sum_{i=1}^{12} f_{i}\right)-12 \omega}(100)
$$

where $\omega$ is the shift in the frequency of driver crash involvement estimated by the time-series model and $f_{i}$ is the actual monthly frequency of crash involvement.

2The moving average trend lines depicted in Figures 3 through 6 are simple front-ended 12 -month moving av. erages calculated as follows:

$$
X_{t}=\frac{Y_{t}+Y_{t-1}+Y_{t-2}+Y_{t-3}+\ldots Y_{t-11}}{12}
$$

flects the recurring seasonal pattern of low alcohol-related crash involvement in the winter months and high crash involvement in the summer and fall months. This seasonal cycle was filtered out before estimating the crash reduction associated with the drinking age change.

Non-alcohol-related property damage crash involvement also decreased significantly for the 18-20 age group, but the magnitude of the decrease was only half as large as that in alcohol-related crashes (Table 1). Subtracting the percent decrease in general non-alcohol-related crash involvement from the percent decrease in alcoholrelated crashes produces a net reduction of 11 to $22 \%$ in alcohol-related property damage crash involvement attributable to the higher drinking age. ${ }^{3}$ This reduction represents 725 to 1617 fewer younger Michigan drivers involved in alcohol-related property damage crashes over the first 12 months with the higher legal age than would have been expected had the drinking age not been increased. The conclusion that the raised drinking age was responsible for these observed crash reductions is strengthened by the results for the older age groups; drivers ages $21-23$ and $24-45$ exhibited no significant change in crash involvement.

A second major finding was no conclusive effect of the raised drinking age on the frequency of property damage crashes among 16 and 17 year old drivers. Although policereported alcohol-related crashes decreased significantly, crashes with no police-reported drinking decreased by about the same amount; as a result, the decrease in alcoholrelated crashes cannot be unambiguously attributed to the drinking age increase.

Similar findings emerge from the analyses of injury and fatal crash involvement in Michigan (Table 2). Police-reported alcohol-related crashes among 18-20 year olds decreased $28 \%$ when the drinking age was raised (Figure 5); single-vehicle nighttime

\footnotetext{
${ }^{3}$ The $11 \%$ estimate is based on a comparison between single-vehicle nighttime male and daytime crashes, and the $22 \%$ estimate is based on a comparison between crashes where police reported drinking and those where no drinking was reported.
} 
TABLE 1

TIME-SERIES MODEL ESTIMATES OF CHANGES IN PROPERTY-DAMAGE-ONLY CRASH INVOLVEMENT ASSOCIATED WITH RAISING THE LEGAL MINIMUM DRINKING AGE IN MICHIGAN

\begin{tabular}{|c|c|c|c|c|c|}
\hline & \multirow[b]{2}{*}{ TYPE OF CRASH } & \multicolumn{4}{|c|}{ DRIVER AGE } \\
\hline & & $16-17$ & $18-20$ & $21-23$ & $24-45$ \\
\hline \multirow[t]{2}{*}{ Alcohol-related } & $\begin{array}{l}\text { Police-reported drinking } \\
\text { Estimate } \\
\text { t-ratio } \\
\text { Percent }\end{array}$ & $\begin{array}{c}-21.4 \\
3.0^{*} \\
-14.7\end{array}$ & $\begin{array}{c}-208.2 \\
7.2^{*} \\
-34.0\end{array}$ & $\begin{array}{r}-7.6 \\
0.5 \\
-1.7\end{array}$ & $\begin{array}{r}44.9 \\
1.2 \\
3.8\end{array}$ \\
\hline & $\begin{array}{l}\text { Single-vehicle Nighttime Male } \\
\text { Estimate } \\
\text { t-ratio } \\
\text { Percent }\end{array}$ & $\begin{array}{r}-34.9 \\
2.6 \\
-15.5\end{array}$ & $\begin{array}{c}-129.4 \\
5.1^{*} \\
-24.0\end{array}$ & $\begin{array}{r}-31.2 \\
2.3 \\
-8.8\end{array}$ & $\begin{array}{r}-20.7 \\
0.5 \\
-2.5\end{array}$ \\
\hline \multirow[t]{2}{*}{ Non-alcohol-related } & $\begin{array}{l}\text { No police-reported drinking } \\
\text { Estimate } \\
\text { t-ratio } \\
\text { Percent }\end{array}$ & $\begin{array}{c}-400.2 \\
3.7^{*} \\
-13.3\end{array}$ & $\begin{array}{c}-0.1^{\mathrm{a}} \\
3.0^{*} \\
-12.2\end{array}$ & $\begin{array}{c}-0.1^{\mathrm{a}} \\
2.4 \\
-10.4\end{array}$ & $\begin{array}{l}-0.1^{\mathrm{a}} \\
2.3^{2} \\
-9.5\end{array}$ \\
\hline & $\begin{array}{l}\text { Daytime } \\
\text { Estimate } \\
\text { t-ratio } \\
\text { Percent }\end{array}$ & $\begin{array}{c}-324.2 \\
3.4^{*} \\
-13.3\end{array}$ & $\begin{array}{c}-539.9 \\
2.9^{*} \\
-12.8\end{array}$ & $\begin{array}{r}-315.5 \\
2.0 \\
-9.6\end{array}$ & $\begin{array}{r}-1186.7 \\
2.4 \\
-10.0\end{array}$ \\
\hline
\end{tabular}

aSeries logarithmically transformed to reduce heteroscedasticity; estimate based on transformed series.

${ }^{*} p<0.01$, two-tailed test.

male crashes decreased $22 \%$ (Figure 6). Daytime injury and fatal crashes also decreased significantly for this age group, but the magnitude of the decrease was only half as large as the decrease in nighttime crashes. If one subtracts the $11 \%$ decrease in daytime crashes from the $22 \%$ decrease in single-vehicle nighttime male crashes, an $11 \%$ reduction in alcohol-related accidents remains attributable to the raised drinking age. Since there was no significant change in crashes with no police-reported drinking,

FIGURE 3

POLICE-REPORTED DRINKING DRIVERS

AGES 18-20 INVOLVED IN PROPERTY DAMAGE CRASHES IN MICHIGAN

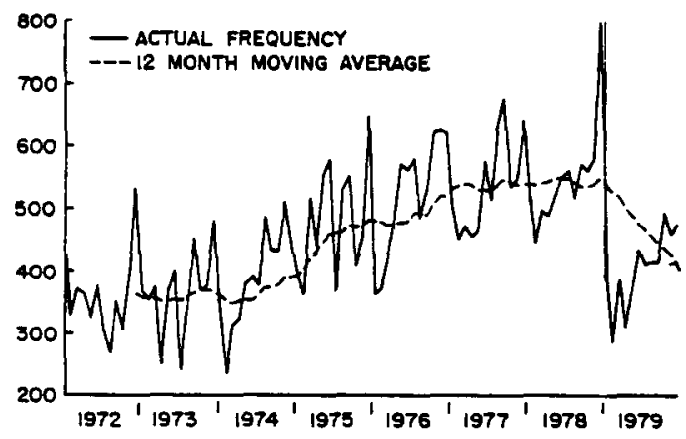

the $28 \%$ reduction in police-reported alcohol-related accidents also can be considered an estimate of the effect of the drinking age change.

In short, raising the drinking age resulted in an 11 to $28 \%$ reduction in alcohol-related injury and fatal motor vehicle crashes. This 11 to $28 \%$ reduction represents 373 to 1726 fewer young drivers involved in injury and fatal crashes over the first 12 months after the drinking age increase than would have been expected had the law not been changed.

FIGURE 4

MALE DRIVERS AGES 18-20 INVOLVED IN LATENIGHT, SINGLE-VEHICLE, PROPERTY DAMAGE CRASHES IN MICHIGAN

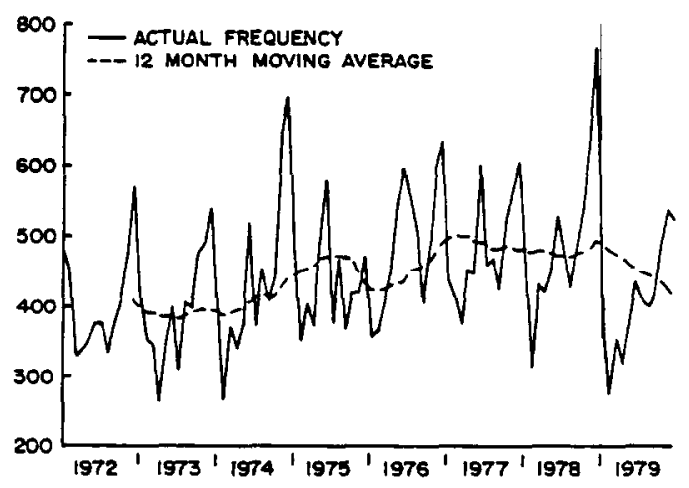


TABLE 2

TIME-SERIES MODEL ESTIMATES OF CHANGES IN INJURY/FATAL CRASH INVOLVEMENT ASSOCIATED WITH RAISING THE LEGAL MINIMUM DRINKING AGE IN MICHIGAN

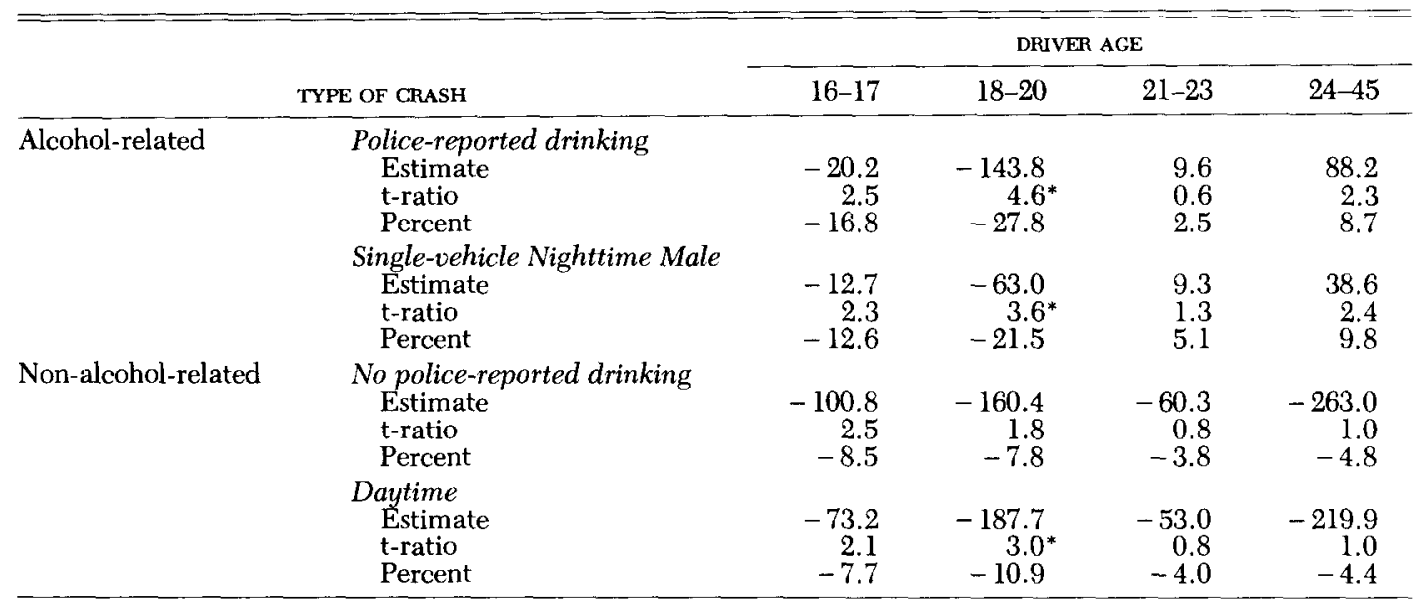

${ }^{*} p<0.01$, two-tailed test.

The conclusion that these reductions are due to the drinking age is strengthened by finding no significant changes in alcohol-related or non-alcohol-related crashes among drivers ages $21-23$ or $24-45$.

As for property damage crashes, no significant effect of the raised drinking age was found on injury and fatal crash involvement among Michigan drivers ages 16 and 17 .

The analyses were repeated for the state of New York, which did not change its legal minimum drinking age during the 1970s.

FIGURE 5

POLICE-REPORTED DRINKING DRIVERS AGES 18-20 INVOLVED IN CRASHES IN MICHIGAN INCLUDING AT LEAST ONE INJURY OR FATALITY

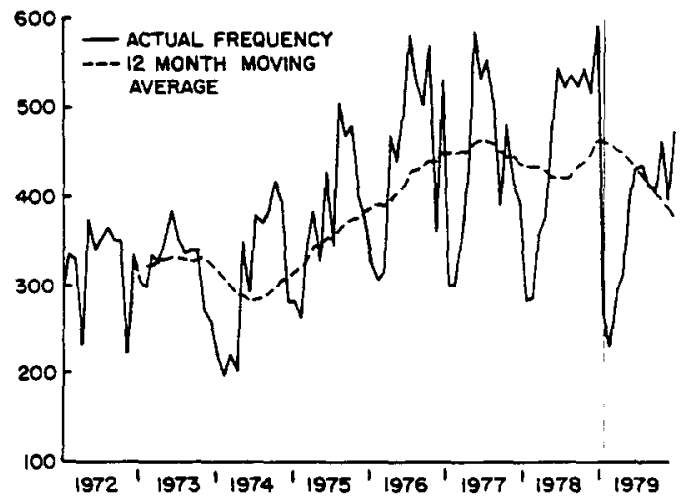

There were no significant decreases in alcohol-related crash involvement among young drivers at the time Michigan raised the drinking age. This cross-state comparison, along with comparisons between alcoholrelated and non-alcohol-related crashes and between younger and older drivers, effectively rules out alternative explanations for the observed significant reductions in alcohol-related crashes among young drivers in Michigan after the drinking age was increased.

The substantial effect of the raised drink-

FIGURE 6

MALE DRIVERS AGES 18-20 INVOLVED IN LATENIGHT, SINGLE'VEHICLE' CRASHES IN MICHIGAN INCLUDING AT LEAST ONE INJURY OR FATALITY

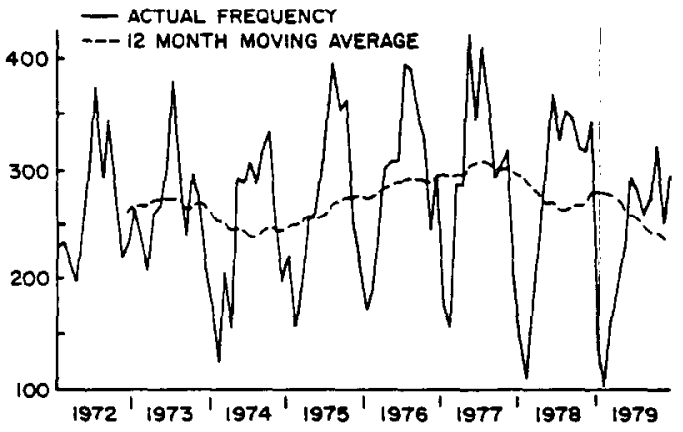


ing age identified through analyses of multiple crash time series was verified by a more rudimentary examination of the frequency of arrests for Driving Under the Influence of Liquor (DUIL) in Michigan. ${ }^{4}$ DUIL arrests for 18-20 year old drivers decreased $8.5 \%$ from 1978 to 1979 , in contrast to $20 \%$ increases in frequency of arrest for drivers 21 and over (Table 3).

Some of the higher arrest rates among drivers 21 and over might have been due to incrcased attention given the drinking-driving problem in recent years. Most of the increase, however, was due to a change in Michigan law in 1978 (Public Law 384 and 391 of 1978), allowing police officers to arrest intoxicated drivers at crash scenes without a warrant. Prior to this change in policy, officers could not arrest a person for DUIL unless they personally witnessed a driver actually operating a motor vehicle while under the influence. As a result, prior to August 1978, numerous crash-involved drivers who had obviously been driving under the influence prior to the crash were not arrested, since the officer did not personally witness the impaired driving.

It might be safely assumed that 18-20 year old drivers would have experienced the same $20 \%$ increase in DUIL arrests as a result of the warrantless arrest law that 21-23 year olds experienced, if there had been no reduction in drinking-driving due to the higher drinking age. Given this assumption, the actual number of DUIL arrests among 18-20 year old drivers in 1979 was an estimated $29 \%$ (i.e., $20 \%$ plus $9 \%$ ) lower than expected had the drinking age not been changed. Although the lack of analyses of extended time series makes one less confident of the arrest findings than the crash findings, the unexpected decrease in DUIL arrests among young drivers provides further evidence that the amount of impaired driving was significantly reduced by the increase in drinking age.

One question that has not been adequately addressed is the long-term effects of a

${ }^{4}$ The assistance of Lyle D. Filkins of The University of Michigan Highway Safety Research Institute with collection, analysis, and interpretation of the DUIL arrest data is gratefully acknowledged.
TABLE 3

NUMBER OF DRIVERS ARRESTED FOR DRIVING UNDER THE INFLUENCE OF LIQUOR IN MICHIGAN

\begin{tabular}{lrrr}
\hline & \multicolumn{3}{c}{ YEAR } \\
\cline { 2 - 3 } AGE & 1978 & 1979 & \% Change \\
\hline $13-17$ & 706 & 789 & 11.8 \\
$18-20$ & 4,412 & 4,035 & -8.5 \\
$21-23$ & 4,283 & 5,156 & 20.4 \\
$24-44$ & 15,993 & 19,456 & 21.6 \\
\hline
\end{tabular}

raised drinking age. Studies to date have, of necessity, been limited to one or two years of post-intervention data. Although detailed time-series analyses of monthly crash data for the early 1980s have not yet been completed, annual totals of crash-involved drinking drivers are shown in Figure 7. The substantial decrease in alcohol-related crash involvement among 18-20 year-old drivers from 1978 to 1979 is again clearly evident. This contrasts with 21-24 year old drivers, who continued their upward trend in 197879 .

FIGURE 7

POLICE-REPORTED DRINKING DRIVERS INVOLVED IN MOTOR VEHICLE CRASHES IN MICHIGAN

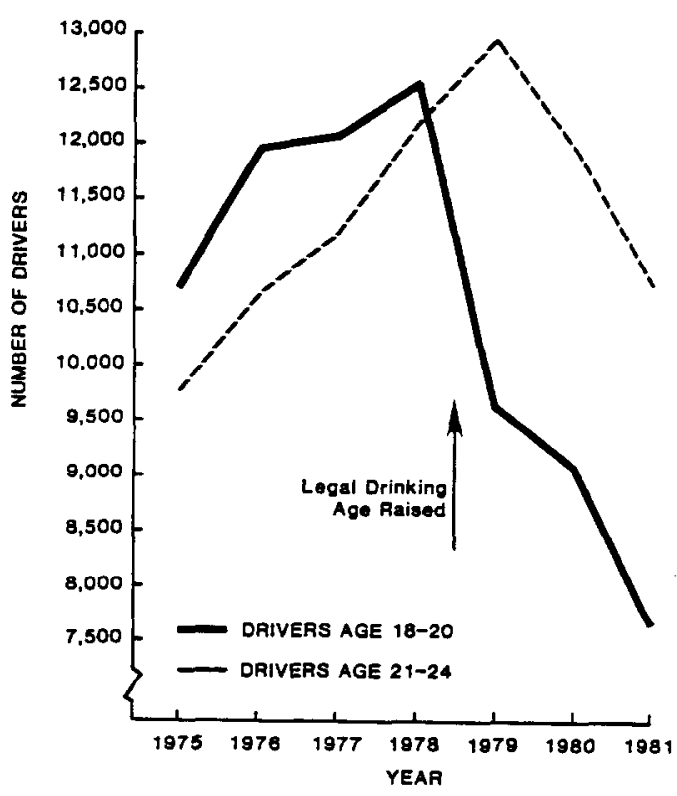


It is also clear that both the $18-20$ and 21-24 age groups experienced reduced alcohol-related crash involvement in 1980 and 1981. The reductions for 1980 and 1981 , which occurred for drivers of all ages (data not shown), were probably a result of the severe economic recession in Michigan, as well as other highway safety programs during those years. In any event, the crash reductions among 18-20 year old drivers resulting from the drinking age change do not appear to be a temporary phenomenon. The drinking age crash reductions were maintained in 1980 and 1981, and young drivers experienced further crash reductions similar to those experienced by drivers of all ages in Michigan. These results are consistent with the findings of multi-year follow-ups of the effects of drinking age reductions in the early 1970 s, which identified permanent increases in alcohol-related crash involvement after lowering the legal drinking age.

\section{DISCUSSION}

Alcohol-related crash involvement among young drivers clearly decreased after the legal minimum drinking age was raised in Michigan. The observed crash reductions estimated with comprehensive time-series models can be causally attributed to the change in drinking age due to the pattern of findings across three levels of control groups. Substantial reductions in DUIL arrests provided further evidence that the higher legal drinking age reduced impaired driving among youth. Finally, comparisons between the effects of Michigan's lowering the legal drinking age from 21 to 18 (effective January 1972) and of returning the drinking age to 21 reveal remarkably similar impact magnitudes. Douglass and Freedman (1977) found 17 to $35 \%$ increases in alcohol-related crash involvement anong 18-20 year old drivers after Michigan lowered its drinking age. The 11 to $22 \%$ crash involvement decreases identified in this study indicate that returning to the higher drinking age reversed the adverse highway safety effects of the 7-year experiment with a lower drinking age.

No unequivocal effects of the raised drinking age on underage (16-17) drivers were found the first year after the change. In a study of Ontario's reduction in legal age, Whitehead, Craig, Langford, MacArthur, Stanton, and Ferrence (1975) found little effect on underage drivers in the first year with the new law, but alcohol-related crashes increased in the second year. Whether such delayed effects may occur after raising the drinking age remains an issue for further research, using multi-year follow-up data.

Of the studies conducted to date on the effect of returning to higher drinking ages, those with the most sophisticated design and analysis methods found significant reductions in drinking driving or alcohol-related crash involvement after states raised the drinking age.

Massachusetts appears to be one exception to this general conclusion. Only very small effects of the raised drinking age in Massachusetts have been reported. Aside from the preliminary nature of the analyses, a possible reason for the lack of a clear effect is that four of the five states bordering Massachusetts had minimum drinking ages of 18 after Massachusetts raised its drinking age. ${ }^{5}$ The availability of beverage alcohol to Massachusetts youth was not reduced as much as in other states that raised the drinking age, since Massachusetts youth had a legal supply of alcohol in contiguous states. Hingson's (1981) survey results provide some support for this line of reasoning, since underage Massachusetts youth reported little difficulty obtaining alcohol after the drinking age was raised.

Evidence that contiguous states with lower minimum drinking ages create problems with cross-border purchases of alcohol by youth was provided by Lillis, Williams, and Williford (1981). They found an overrepresentation of 18-20 year old Pennsylvania residents in alcohol-related traffic crashes occurring in New York counties con-

\footnotetext{
sVermont, New York, Connecticut, and Rhode Island permitted 18 year olds to purchase all types of alcoholic beverages during the period for which the Massachusetts law was evaluated. New Hampshire increased its drinking age from 18 to 20 in May 1979 , just one month after the Massachusetts increase was implemented.
} 
tiguous with Pennsylvania, although the size of the effect was small. ${ }^{6}$

Another potential explanation of the lack of an observed effect in Massachusetts is the data analyzed. In both studies of the Massachusetts experience (Hingson et al., 1981; Williams et al., 1981), the dependent variable, fatal crash involvement, had low frequencies. As noted earlier, the number of alcohol-related crash fatalities among a limited age group in one state is relatively small for analysis purposes. As a result, the large random variation in the number of fatalities from month to month, or even year to year, makes it difficult to identify a significant effect of a policy change such as the raised drinking age. Even in Michigan, where major reductions in both injury-producing and property damage crash involvement clearly resulted from the raised drinking age, no significant effect was discernible when fatal crashes alone were analyzed (Wagenaar, 1980). The problems with low crash frequencies for analysis might also emerge for nonfatal crashes in less populous states like Maine, making it more difficult to detect any effect of drinking age changes. As a result, while the preponderance of evidence to date clearly demonstrates an effect of raising the drinking age, reductions in crashes and injuries may not always be evident in less populous jurisdictions or jurisdictions where analyses are limited to fatal crashes.

One implication of these findings for luture evaluations is that analyses should not be limited to fatalities, but should also include the much larger numbers of injury and property damage crashes. Although the effort and costs associated with analyzing nonfatal crashes are substantially higher, such analyses may avoid incorrect conclusions.

In addition to the Massachusetts study, Vingilis and Smart's (1981) evaluation of Ontario's raised drinking age found no significant effect on traffic crashes. The lack of an observed effect in Ontario may also be due to the insensitive indicators used, crash fatalities and drinking-driving convictions.

${ }^{6}$ The minimum drinking age was 21 in Pennsylvania and 18 in New York at the time of this study.
Another important consideration is the grandfather clause in Ontario's law, which substantially reduced the number of young drivers whose drinking privileges were removed during the first year under the higher drinking age. As a result, little effect of the raised drinking age was expected immediately after implementation of the new law. Future research must take into account such grandfather clauses to avoid concluding prematurely that the drinking age change has no effect.

In spite of these two exceptions, the literature to date provides convincing evidence that both lowering and raising the legal minimum drinking age have direct implications for public health and safety. The mechanisms through which drinking age laws affect drinking-driving, however, are not yet clearly understond. While it is generally assumed that the higher legal drinking age results in less alcohol consumed by youth, aggregate analyses to date have revealed no consistent relationship (Wagenaar, in press, $b$ ). It is not clear whether the beneficial effects of higher drinking ages are due to: (1) reduced quantity of alcohol consumed by youth on each drinking occasion; (2) fewer drinking occasions; (3) changes in drinking locations so that less driving while impaired is required; (4) more cautious driving while impaired; or (5) some combination of these effects. Further research is needed to clarify the effects of changes in legal drinking age on the drinking and driving-after-drinking patterns among youth.

Finally, some comments on the policy implications of the findings reported here are warranted. In spite of the demonstrated substantial effect of the raised drinking age in reducing alcohol-related crashes among young drivers, it is important to keep in mind that changing the drinking age does not eliminate this very serious public health problem. If a raised drinking age reduces the problem by $20 \%$, by implication $80 \%$ of the alcohol-related crashes are continuing to occur and require continuing prevention efforts. If large numbers of alcohol-related crashes continue to occur among underage drivers, it is clear that some young people are continuing to drink and therefore must still have alcohol available to them. Raising 
the legal minimum drinking age does not eliminate the availability of alcohol to young people, but rather reduces alcohol availability and the public health problems associated with it.

Minimum purchasing ages have never prevented underage youth from drinking. There are numerous surveys indicating that a majority of high school youths are not abstainers. Is it not reasonable to expect a raised legal drinking age to eliminate all youthful alcohol consumption. The observation that youths continue to drink after implementation of higher drinking ages has been cited in the popular media as evidence that the laws have no effect. Nevertheless, evaluation of any prevention policy or program is based on marginal effects in reducing public health problems. No prevention effort is realistically expected to prevent all of the incidence of a public health problem. The legal minimum drinking age substantially reduces alcohol-related crash involvement among young drivers; that it does not eliminate this serious problem is no reason to reject minimum drinking age as one component of a broader prevention effort.

\section{REFERENCES}

Box, G. E. P., \& Jenkins, G. M. Time series analysis: Forecasting and control (Rev. ed.). San Francisco: Holden-Day, 1976.

Box, G. E. P., \& Tiao, G. C. Intervention analysis with applications to economic and environmental problems. Journal of the American Statistical Association, $1975,70,70-79$.

Cameron, T. Alcohol and traffic. In M. Aarens et al., Alcohol, casualties and crime. Berkeley: University of California, School of Public Health, 1977.

Chu, B., \& Nunn, G. E. An analysis of the decline in California traffic fatalities during the energy crisis. Accident Analysis and Prevention, 1976, 8, 145-150.

Cook, T. D., \& Campbell, D. T. Quasi-experimentation: Design and analysis issues for field settings. Chicago: Rand McNally, 1979.

Douglass, R. L., Filkins, L. D., \& Clark, F. A. The effect of lower legal drinking ages on youth crash involvement. Ann Arbor: Highway Safety Research Institute, The University of Michigan, 1974.

Douglass, R. L., \& Freedman, J. A. Alcohol-related castualties and alcohol beverage market response to beverage alcohol availability policies in Michigan. Ann Arbor: Highway Safety Research Institute, The University of Michigan, 1977.

Filkins, L. D., \& Flora, J. D. Alcohol-related accidents and DUIL arrests in Michigan: 1978-1979. Ann Arbor: Highway Safety Research Institute, The Univer- sity of Michigan, March, 1978.

Gottman, J. M. Time-series analysis: A comprehensive introduction for social scientists. New York: Cambridge University Press, 1981.

Hibbs, D. A., Jr. On analyzing the effects of policy interventions: Box-Jenkins and Box-Tiao versus structural equation models. In D. R. Heise (Ed.), Sociological Methodology 1977. San Francisco: JosseyBass, 1977.

Hingson, R., Scotch, N., Meyers, A., et al. Impact of legislation raising the legal drinking age in Massachusetts from 18 to 20 years. Paper presented at the 109 th Annual Meeting of the American Public Health Association, Los Angeles, November 1-5, 1981

Jones, R. K., \& Joscelyn, K. B. Alcohol and highway safety: A review of the state of knowledge. Ann Arbor: Highway Safety Research Institute, the University of Michigan, 1978.

Joscelyn, K. B., Jones, R. K., \& Ruschmann, P. A. Alcohol and highway safety. Ann Arbor: Highway Safety Researdi Institute, The University of Michigan, 1981.

Klein, $\mathbf{T}$. The effect of raising the minimum legal drinking age on traffic accidents in the State of Maine. Washington, D.C.: National Highway Traffic Safety Administration, 1981.

Lillis, R., Williams, T., \& Williford, W. Reported alcohol crashes involving 18-21 year old Pennsulvania drivers in ten New York border counties (Research Report Series Number 10). Albany: New York State Division of Alcoholism and Alcohol Abuse, Bureau of Alcohol and Highway Safety, 1981.

Liu, L-M. User's manual for BMDQ2T (TSPACK) time series analysis (Box-Jenkins) (Technical Report 57). Los Angeles: University of California, Department of Biomathematics, 1979.

Maxwell, D. M. Impact analysis of the raised legal drinking age in lllinois. Washington, D.C.: National Highway Traffic Safety Administration, 1981.

McCleary, R., \& Hay, R. A., Jr. Applied time series analysis for the social sciences. Beverly Hills: Sage Publications, 1980.

National Highway Traffic Safety Administration, Evaluation of minimum drinking age laus using the na tional electronic injury surveillance system. Washington, D.C.: Author, 1982.

O'Day, J., Minahan, D. J., \& Golomb, D. The effects of the energy crisis and $55 \mathrm{mph}$ speed limit in Michigan. Ann Arbor: Highway Safety Research Institute, The University of Michigan, 1975.

Smart, R. G., \& Goodstadt, M. S. Effects of reducing the legal alcohol-purchasing age on drinking and drinking problems: A review of empirical studies. Journal of Studies on Alcohol, 1977, 38, 1313-1323.

Vingilis, E., \& Smart, R. G. Effects of raising the legal drinking age in Ontario. British Journal of Addiction, $1981,76,415-424$.

Voas, R. B., \& Moulden, J. Historical trends in alcohol use and driving by young Americans. In $\mathrm{H}$. Wechsler (Ed.), Minimum-drinking-age laws. Lexington, Massachusetts: Lexington Books, 1980.

Wagenaar, A. C. Effects of an increase in drinking age. Journal of Public Health Policy, 1981, 2, 206-225.

Wagenaar, A. C. The minimum legal drinking age: $A$ 
time series impact evaluation. Unpublished doctoral dissertation, The University of Michigan, 1980.

Wagenaar, A. C. Raising the legal drinking age in Maine: Impact on traffic accidents among young drivers. International Journal of the Addictions, in press. (a)

Wagenaar, A. C. Aggregate beer and wine consumption: Effects of changes in the minimum legal drinking age and a mandatory beverage container deposit law. Journal of Studies on Alcohol, in press. (b)

Whitehead, P. C. Alcohol and young drivers: Impact and implications of lowering the drinking age. Ottawa, Ontario: Department of National Health and Welfare, Non-medical Use of Drugs Directorate, 1977.

Whitehead, P. C. Research strategies to evaluate the impact of changes in the legal drinking age. In $\mathrm{H}$.
Wechsler (Ed.), Minimum-drinking-age laws. Lexington, Massachusetts: Lexington Books, 1980.

Whitehead, P. C., Craig, J., Langford, N., MacArthur, C., Stanton, B., Ferrence, R. G. Collision behavior of young drivers: Impact of a change in the age of majority. Journal of Studies on Alcohol, 1975, 36, 12081223.

Williams, A. F., Zador, P. L., Harris, S. S., and Karpf, R. S. The effects of raising the legal minimum drinking age on fatal crash involvement. Washington, D.C.: Insurance Institute for Highway Safety, 1981.

Wiorkowski, J. J., \& Heckard, R. F. The use of time series analysis and intervention analysis to assess the effects of external factors on traffic indices: A case study of the effects of the speed limit reduction and energy crisis in the State of Texas. Accident Analysis and Prevention, 1977, 9, 229-247. 